\title{
Spontaneous Pre-Labour Rupture of Membranes at Term: Immediate versus Delayed Induction of Labour
}

\author{
La Rupture Pré-de la main-d'œuvre Spontanée de Membranes au Terme : \\ Immédiat contre l'Induction Retardée de parti travailliste
}

A. Omole-Ohonsi*, A. Ashimi*, S. Adeleke ${ }^{\dagger}$

\section{ABSTRACT}

BACKGROUND: Spontaneous pre-labour rupture of membranes (SPROM) at term is one of the most common complications of pregnancy. It is an important cause of perinatal morbidity and mortality, particularly because it is associated with a latency period from membrane rupture to delivery. OBJECTIVE: To compare the outcome of labour in women who had immediate induction of labour, with those who had delayed induction following SPROM at term.

METHODS: A prospective case control study of 200 women who had either immediate induction of labour with intravaginal misoprostol tablets, or delayed induction with intravenous oxytocin infusion after an expectant period of 12 hours, at Aminu Kano Teaching Hospital, Kano, Nigeria. The outcome of labour was compared in the two groups using the $\mathrm{Z}$ test and Chi square test, while, $p$-value of less than 0.05 was taken as significant. The odds ratio $(\mathrm{OR})$ and $95 \%$ confidence interval were also determined where appropriate

RESULTS: Immediate induction of labour with intravaginal misoprotol resulted in lower rates of caesarean section and operative vaginal delivery, with a higher rate of spontaneous vaginal delivery. The duration of latent phase of labour and hospital stay before delivery was statistically significantly shorter in the immediate induction group. Neonatal and maternal morbidity were insignificant and comparable between the two groups.

CONCLUSION: Immediate induction of labour with intravaginal misoprotol resulted in significantly lower rates of intervention without compromising fetomaternal outcome. We recommend the immediate induction of labour with proper use of intravaginal misoprotol in women with SPROM at term. WAJM 2009; 28(3): 156-160.
\end{abstract}

Key words: SPROM at term, immediate vs delayed induction of labour, Outcome.

\section{RÉSUMÉ}

CONTEXTE: la rupture pré-de la main-d'œuvre spontanée de membranes (SPROM) au terme est une des complications les plus communes de grossesse. C'est une cause importante de morbidité périnatale et de mortalité, particulièrement parce qu'il est associé à une période(un point) de latence de la rupture membraneuse à la livraison.

OBJECTIF: comparer le résultat de travail dans les femmes qui avaient l'induction immédiate de travail, avec ceux qui avaient retardé l'induction suite à SPROM au terme.

MÉTHODES: un cas potentiel contrôle l'étude de 200 femmes qui avaient l'induction immédiate de travail avec les comprimés misoprostol intravaginaux, ou ont retardél'induction avec l'injection oxytocin intraveineuse après une période (un point) dans l'attente de 12 heures, à l'Hôpital d'Aminu Kano Teaching, Kano, le Nigeria. Le résultat de travail a été comparé dans les deux groupes utilisant l'épreuve de $Z$ et l'épreuve carrée Chi, pendant que, la p-valeur d'entre moins de 0.05 a été prise comme significative. Le rapport de cote $(O U)$ et l'intervalle de confiance de $95 \%$ a été aussi déterminé où approprié

RÉSULTATS: l'induction immédiate de travail avec misoprotol intravaginal avait pour résultat des taux inférieurs(plus bas) de césarienne et de livraison vaginale en vigueur, avec un plus haut taux de livraison vaginale spontanée. La durée de phase latente de travail et de séjour d'hôpital avant la livraison était de façon significative plus courte statistiquement dans le groupe d'induction immédiat. La morbidité néo-natale et maternelle était insignifiante et comparable entre les deux groupes.

CONCLUSION: l'induction immédiate de travail avec misoprotol intravaginal avait pour résultat des taux de façon significative inférieurs(de façon significative plus bas) d'intervention sans compromettre le résultat fetomaternal. Nous recommandons l'induction immédiate de travail avec l'utilisation convenable de misoprotol intravaginal dans les femmes avec SPROM au terme. WAJM 2009; 28(3): 156-160.

Mots clé: SPROM au terme, immédiat contre l'induction retardée de travail, le Résultat.

Departments of *Obstetrics and Gynaecology, ${ }^{\dagger}$ Paediatrics, Bayero University/Aminu Kano Teaching Hospital, Kano, Nigeria. Correspondence: Dr. A. Omole-Ohonsi, Department of Obstetrics and Gynaecology, Aminu Kano Teaching Hospital, P.M.B. 3452, Kano Nigeria.

Abbreviations: CI, Confidence interval; OR, Odds ratio; OVD, Operative vaginal delivery; SPROM, Spontaneous pre-labour rupture of membranes; SVD, Spontaneous vaginal delivery. 


\section{INTRODUCTION}

Spontaneous pre-labour rupture of fetal membranes (SPROM), which is defined as rupture of fetal membranes before the onset of labour complicates five to $10 \%$ pregnancies, with $60 \%$ of them occurring at term. ${ }^{1}$ The management of SPROM at term is controversial. ${ }^{1-7}$ One school of thought believes in the conservative or expectant management, in which an expectant period of 12-24 hours after the incident is observed to allow a good number of women to go into spontaneous labour with high vaginal delivery rate. ${ }^{1-7}$ The other school of thought believes in immediate induction of labour, in which labour is induced immediately after admission irrespective of the duration of rupture of membranes. ${ }^{1-7}$

The concern about delayed induction protocol is the risk of infection to the mother and fetus, with subsequent puerperal and neonatal sepsis. The immediate induction of labour is said to be associated with increased caesarean section rate because of unfavourable cervix. ${ }^{1-4}$ If induction of labour is carried out with intravenous oxytocin infusion in women with unfavourable cervix, the possibility of failed induction approaches $30-40 \%$; the prolonged labour that will ensue increases the risk of maternal and neonatal infection. ${ }^{1,2}$

Oral Misoprostol (porostaglandin) $\mathrm{E}_{1}$ which is cheap, heat stable and easy to store, with better user acceptability has been found in many studies to be efficient and safe in ripening the cervix and inducing labour when inserted

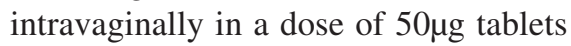
every 4-6 hours. ${ }^{8-16}$ Its efficacy in ripening the cervix and inducing labour, with high vaginal delivery rate and favourable fetomaternal outcome, has brought the return of 'day light obstetrics' with all its conveniences. ${ }^{8}$ This means that if it is used intravaginally to induce labour in the morning, no matter the Bishop score, vaginal delivery will usually be achieved before sunset. ${ }^{8}$

Medication that will ripen the cervix in a short period of time and compress into a day, the process that generally used to take days will play an important role in modern obstetrics ${ }^{16}$ To date no pharmacological agent or technique has been acceptable as a method of induction of labour. ${ }^{10,16}$ It is against this background that this study was carried out to compare the outcome of labour in women who had immediate induction of labour with intravaginal misoprostol, with those who had delayed induction with intravenous oxytocin infusion after an expectant period of 12 hours, and to make recommendations about their efficiency and safety, as well as their acceptability.

\section{SUBJECTS, MATERIALS, AND METHODS}

This prospective observational case control study was conducted in Aminu Kano Teaching Hospital, Kano, Nigeria from $1^{\text {st }}$ January 2004 to compare the pregnancy outcome in the fist 100 women with SPROM at term, who were managed with the expectant or delayed induction of labour with oxytocin infusion policy (control group), with that of the first 100 women with SPROM at term, who were managed with immediate induction of labour using intravaginal misoprostol (study group).

The inclusion criteria were women who (i) ruptured membranes spontaneously at 37 weeks of gestation or more, which was verified from the last normal menstrual period and / or early ultrasound dating; (ii) were carrying single fetus in cephalic presentation; (iii) were not in labour, which was confirmed by absence of uterine contractions over one hour after presentation; (iv) had normal fetal heart rate and reactive tracing on cardiotocograph; (v) had no meconium staining of the liquor; and (vi) had no contraindication to induction of labour or vaginal delivery.

The diagnosis of rupture of fetal membranes was based on (i) history of passage of fluid per vaginam; (ii) fluid seen draining out through the cervical os on speculum examination, especially on bearing down; (iii) presence of pool of fluid in the posterior fornix which changed litmus paper blue, or rubbing the litmus paper on the lateral vaginal walls with the same reaction; and (iv) by ultrasound scan, which revealed reduced liquor volume in addition to a positive litmus paper test.

A high vaginal swab was taken at the time of speculum examination. Digital examination was done after confirming the diagnosis to determine the Bishop score in those who were allocated to the immediate induction group, while it was delayed until the time of induction of labour in the delayed induction group in order to prevent intrauterine infection. Prophylactic antibiotic was given.

In the immediate induction group, labour was induced immediately after admission by insertion of $50 \mu \mathrm{g}$ misoprostol tablet in the posterior fornix, and they were observed closely by the midwives. The insertion of misoprostol was repeated after six hours if the woman had not gone into labour.

In the delayed induction of labour group, they were admitted into the antenatal ward and were closely monitored for onset of labour for 12 hours, before they were transferred to the labour ward for induction of labour if labour had not started.

The variables that were monitored in the antenatal ward during the expectant period included maternal temperature every 4 hours, hourly maternal pulse rate and hour, fetal heart rate, white blood cell count every 4 hours, uterine tenderness, offensive of lochia. Monitoring was terminated before the 12-hour waiting period for induction of labour if these parameters indicated that chorioamnionitis had developed, or for caesarean section if fetal heart rate was abnormal with non-reactive pattern on cardiotocograph, or if the patient went into labour when she was sent back to labour ward to continue with labour monitoring.

Chorioamnionitis was diagnosed when maternal temperature was more than $38^{\circ} \mathrm{C}$ with abnormality in any two of the remaining five indicators, viz maternal tachycardia, fetal tachycardia, maternal leucocytosis, uterine tenderness and offensive lochia.

If labour did not start in 12 hours after admission and monitoring parameters were normal, the woman was transferred to labour ward, and induction of labour was commenced with 5 units of oxytocin in 500mls of 5\% dextrose water which was titrated against uterine contractions starting with $2 \mathrm{mIU} /$ minute. The oxytocin rate was doubled every 30 minutes until 3-5 contractions were obtained in 10 minutes which lasted 40 
60 seconds each, or until a maximum infusion rate of $32 \mathrm{mIU} / \mathrm{minute}$ was achieved.

In both groups labour was monitored using partograph. Vaginal examination was done every 4 hours, and the findings were recorded on the partograph. Labour monitoring was terminated for caesarean section when there was failure to progress or if fetal distress developed when delivery was not imminent.

Failure to progress in the latent phase of labour was taken as the woman not yet in active phase of labour over a period of 24 hours in a primigravidae and 14 hours in a multigravidae. Failure to progress in the active phase of labour, was taken as failure of further cervical dilatation after $3 \mathrm{~cm}$ dilatation, in the presence of adequate uterine contractions, with the graph of the woman's progress of labour reaching the action line on the partograph. Failure to progress in the second stage of labour, was taken as absence of further descent of the fetal head over a period of 2 hours in primigravidae, and one hour in multigravidae in the presence of adequate uterine contractions. Fetal distress was taken as a fetal heart rate of less than 120 beats/minute or more than 160 beats/ minute, with a non-reactive fetal heart tracing on cardiotocograph.

The parameters that were checked in the newborn at birth were Apgar score at 1 and 5 minutes and umbilical cord blood samples were taken for white cell count and culture. The babies were handed over to the paediatrician for other tests and treatment.

Analysis of data done using frequencies, mean and standard deviation. Z-test and Chi square test were used to compare differences between categorical variables. Univariate and multivariate logistic regression analysis were performed where appropriate, and the results were expressed as odds ratio (OR) with $95 \%$ confidence interval (CI).

\section{RESULTS}

Two hundred women participated in the study. One hundred women had immediate induction of labour with intravaginal misoprostol, and the same number of women had delayed induction with oxytocin infusion after an expectant period of 12 hours. Thirty-three percent of the women in the delayed induction group went into spontaneous labour before induction with oxytocin infusion. Among the women in the immediate induction group, $94 \%$ required only one insertion of misoprostol for induction of labour, while $21 \%$ of the women in the immediate induction group, and $82 \%$ among those in the delayed induction group, required augmentation of labour with oxytocin infusion. There was no significant difference in the neonatal outcome between the two groups. The general characteristics of the women did not show any statistically significant difference $(\mathrm{p}>0.05)$ between the two groups. (Table 1).

The mode of delivery showed statistically significant difference $(p<$

$0.05)$ among the two groups. There was lower occurrence of caesarean section $(\mathrm{OR}=0.18, \mathrm{CI}=0.07-0.47)$, and operative vaginal delivery $(\mathrm{OR}=0.26, \mathrm{CI}=0.07$ 0.88 ), with higher occurrence of vaginal delivery $(\mathrm{OR}=6.10, \mathrm{CI}=2.76-13.75)$ among the immediate induction group. (Table 2).

There was no statistically significant difference $(\mathrm{P}>0.05)$ between the two groups in the occurrence of fetal distress, postpartum fever, duration of active phase of labour and number of vaginal digital examinations. Duration of latent phase of labour and duration of hospital stay before delivery showed statistically significant difference $(\mathrm{P}<0.05)$ between the two groups, with shorter latent phase of labour and duration of hospital stay before delivery among the immediate induction group. (Table 3 ).

Table 1: General Characteristics of Participants

\begin{tabular}{|c|c|c|c|}
\hline \multirow[t]{2}{*}{ Variable } & Type of Induction & \multirow[t]{2}{*}{$P$ value $\mathrm{OR}$} & \multirow[t]{2}{*}{$\mathbf{C I}$} \\
\hline & Delayed & & \\
\hline Number & 100 & 100 & \\
\hline Mean age (years) & $22.3 \pm 3.4$ & $22.8 \pm 4.3$ & $>0.05(\mathrm{~N} / \mathrm{S})$ \\
\hline Mean gestational age (weeks) & $38.5 \pm 1.2$ & $38.2 \pm 1.1$ & $>0.05(\mathrm{~N} / \mathrm{S})$ \\
\hline Mean parity & $3.14 \pm 2.0$ & $3.4 \pm 1.83$ & $>0.05(\mathrm{~N} / \mathrm{S})$ \\
\hline \multicolumn{4}{|l|}{ Bishop score } \\
\hline$<6$ & 69 & 67 & $>0.05(\mathrm{~N} / \mathrm{S})$ \\
\hline$>6$ & 33 & 31 & \\
\hline $\begin{array}{l}\text { Positive vaginal } \\
\text { microbial culture }\end{array}$ & 7 & 9 & $>0.05(\mathrm{~N} / \mathrm{S})$ \\
\hline
\end{tabular}

$\mathrm{N} / \mathrm{S}=$ not statistically significant

Table 2: Mode of Delivery Among Participants

\begin{tabular}{llllll}
\hline Variable & \multicolumn{2}{l}{ Type of Induction } & P value OR & CI \\
\cline { 2 - 4 } & Immediate & Delayed & & & \\
\hline Number & 100 & 100 & & & \\
Caesarean section & $7(7 \%)$ & $29(29 \%)$ & $<0.05$ & 0.18 & $0.07-0.47$ \\
OVD & $4(4 \%)$ & $14(14 \%)$ & $<0.05$ & 0.26 & $0.07-0.88$ \\
SVD & $89(89 \%)$ & $57(57 \%)$ & $<0.05$ & 6.10 & $2.76-13.75$ \\
\hline
\end{tabular}

CI, confidence interval; OR odds ratio OVD; Operative Vaginal Delivery; SVD, Spontaneous Vaginal Delivery. 
Table 3: Duration of Labour and Maternal Outcome

\begin{tabular}{lccc}
\hline Variable & \multicolumn{2}{c}{ Type of Induction } \\
Immediate & $\begin{array}{c}\text { Delayed } \\
\mathbf{1 0 0}\end{array}$ & P value \\
$\begin{array}{l}\text { Number } \\
\text { phean duration of latent }\end{array}$ & $\mathbf{1 0 0}$ & $5.8 \pm 4.1$ & \\
$\begin{array}{l}\text { Mean duration of active } \\
\text { phase of labour (hours) }\end{array}$ & $3.6 \pm 2.3$ & $3.4 \pm 2.0$ & $<0.05$ \\
$\begin{array}{l}\text { Mean duration of hospital } \\
\text { stay before delivery (hours) }\end{array}$ & $10.8 \pm 5.6$ & $18.9 \pm 8.4$ & $>0.05$ \\
$\begin{array}{l}\text { Fetal distress } \\
\text { Postpartum fever }\end{array}$ & 3 & 4 & $<0.05$ \\
$\begin{array}{l}\text { Number of vaginal examinations } \\
\quad<4\end{array}$ & 2 & 2 & $>0.05$ \\
$\quad 6-8$ & 38 & 54 & $>0.05$ \\
& & 46 & $>0.05$ \\
\hline
\end{tabular}

\section{DISCUSSION}

In this study, there was no statistically significant difference in the mean age and parity, gestational age at presentation, Bishop score and number of positive vaginal cultures for microbial organisms between the two groups of women, probably because they were all from the same population. This eliminated bias in terms of these factors in the outcome of this study.

In the immediate induction group, $94.0 \%$ of the women required only a single insertion of misoprostol tablet for induction of labour, which is similar to the findings of other authors. ${ }^{12-14}$ This may be because of higher uterine concentrations of misoprostol due to direct absorption from the posterior fornix, and the local effect of misoprostol on the uterine cervix, added the higher concentration of endogenous prostaglandins in the choriodecidual space following SPROM. ${ }^{11-14}$ This higher concentration of endogenous prostaglandins in the choriodecidual space could also explain why $33.0 \%$ of the women in the delayed induction group went into spontaneous labour during the expectant period.

The significantly lower caesarean section rate, operative vaginal delivery rate, and higher spontaneous vaginal delivery rate, with less need for oxytocin augmentation among the women in the immediate induction group in this study concurs with the findings of other authors. ${ }^{12-14}$ Various studies have reported that with adequate vigilance, intravaginal insertion of misoprostol is efficient and ripening of the cervix and induction of labour, with an induction - delivery interval of not more than 12 hours whatever the Bishop score. ${ }^{8-10}$ Its potency has changed the face of our obstetric practice, where it was earlier believed that immediate induction of labour was associated with higher caesarean section rate because of unfavourable cervix, ${ }^{1,10}$ but with the advent of misoprostol vaginal delivery is now achieved in a reasonable period of time especially in an unripe cervix..$^{10,16}$

In the immediate induction group, induction to active phase, induction to delivery, and admission to delivery intervals were statistically significantly shorter, but there was no difference in the rate of progress of labour in the two groups once active phase was reached. These findings are similar to that of other studies. ${ }^{13-15}$ This may be due to the better efficiency of misoprostol in ripening an unfavourable cervix and progressing to the active phase of labour, and partographic monitoring of labour, which was used to ensure efficient uterine action in the two groups throughout the active phase of labour, by augmentation of labour with titrated oxytocin infusion where there was inefficient uterine action.

Maternal and Perinatal morbidity which were insignificantly low and comparable in the two groups, was probably due to meticulous care, and is similar to the experience of other authors. ${ }^{13-15}$ However, it did not agree with safe when used in appropriate dose for the findings in some other studies, where higher maternal and neonatal infection rates were found among the delayed induction group. ${ }^{3}$ This might be because they observed their women for four days before inducing labour, while in our study we observed our women for 12 hours. The risk of infection at term with SPROM is small in the first 24 hours and has been reported as less than $10 \%$, which increase to $24 \%$ after 24 hours of SPROM., ${ }^{1,5}$ This informed our choice of 12 hours expectant period.

\section{Conclusion and Recommendation}

Women who had immediate induction of labour with intravaginal misoprostol appear to be at a lower risk of intervention and to have shorter duration of hospital stay without compromising fetomaternal outcome. We recommend the proper use of intravaginal misoprostol tablets for immediate induction of labour in women with SPROM at term. However, more studies will be required in order to accept this method of induction of labour as the method of choice.

\section{REFERENCES}

1. Jazayeri A, Galan H, Suzanne T. Premature rupture of membranes. emedicine. 2006. http://www. emedicine.com/med/topic3246.htm.

2. Kongnyuy EJ, Chiabi A, Nkele N, Doh AS. Premature rupture of membranes: many questions still unanswered. Clinics in mother and child. 2004; 1: 115-24.

3. Hannah ME, Ohisson A, Farine D, Sheila A, Hewson BA, Ellen D et al. Induction of labour compared with expectant management at home or in hospital? The TermPROM study group. $N$ Engl J Med. 1996; 334: 1005-10.

4. Hannah ME, Hodnett ED, Willan A, Foster GA, DIcecco R, Helewa M. et al. Prelabour rupture of the membranes at term: expectant management at home or in hospital? The TermPROM study group. Obstet. Gynaecol. 2000; 96: 533 8.

5. Tan BP, Hannah ME. Oxytocin for prelabour rupture of membranes at or near term. Cochraine Database Syst. Rev. 2000; (2): CD000157.

6. Mozurkewich E. Management of premature rupture of membranes at term: an evidence-based approach. Clin Obstet Gynaecol. 1999; 42: 749-56.

7. ACOG Practice Bulletin Number 1: clinical management guidelines for 
Obstetrician-Gynaecologists. Premature rupture of membranes. 1988

8. Wagner M. Misoprostol (cytotec) for labour induction. A cautionary tale. Midwifery today. 2003; 67: 1-6.

9. Kwawukume EY, Ayertey RP. The use of misoprostol for induction of labour in a low-resource setting. Trop J Obstet Gynaecol. 2002; 19: 78-81.

10. Soni N, Rayput P. Comparative study between tablet misoprostol (Prostaglandin $\mathrm{E}_{1}$ ) and Dinoprostone GEL for the induction of labour. J Obstet Gynaecol Ind. 2004; 54: 554-555.

11. Sakhare AP, Mahale AR, Kardile GP. Vaginal misoprostol for medical evacuation of missed abortion. J Obst Gynaecol Ind. 2005; 55: 178-9.

12. Wing DA, Paul RH. A comparison of differing dosing regimens of vaginally administered misoprostol for pre induction cervical ripening and labour induction. Am J Obstet Gynaecol. 1990; 180: $1155-1160$.

13. Ferguson JE, Head BH, Frank FH, Frank ML, Singer JS, Stefos T. et al. Misoprostol versus low dose oxytocin for cervical ripening: A prospective, randomized, double mask trial. Am. J. Obstet. Gynaecol. 2002; 187: 273-80.

14. Sanchez-Ramos L, Kaunitz AM, Del Valle Go, Delke I. Schroeder PA,
Bariones DK et al. Labour induction with the prostaglandin E, methyl analogue misoprostol versus oxytocin: a randomized trial. Obstet Gynaecol. 1993; 81: 332-6.

15. Kramer RL, Gilson GJ, Morrison DS, Martin D, Gonzales JL, Qualls C et al. A randomized trial of misprostal and oxytocin for induction of labour: safety and efficacy. Obstet Gynaecol. 1997; 89: 387-91.

16. Patil KP, Swamy MK, Rao RK. Oral misoprostol vs intra-cervical dinoprostone for cervical ripening and labour induction. J Obstet Gynaecol Ind 2005; 55: 128-31. 